\title{
ST Waveform Analysis
}

National Cancer Institute

\section{Source}

National Cancer Institute. ST Waveform Analysis. NCI Thesaurus. Code C92889.

A method of fetal ECG surveillance during labor that monitors the ST segment, to indicate any fetal hypoxia. 